Z Rheumatol 2010 - 69:291

DOI 10.1007/s00393-010-0624-2

Online publiziert: 20. März 2010

๑) Springer-Verlag 2010

J. Schölmerich

Klinik und Poliklinik für Innere Medizin I, Universitätsklinikum Regensburg

\title{
Die Innere Medizin und ihre Schwerpunkte
}

Liebe Kolleginnen und Kollegen,

die acht Schwerpunkte der Inneren Medizin mit ihren eigenen Jahrestagungen und Zeitschriften bilden das Fundament der Deutschen Gesellschaft für Innere Medizin (DGIM). Diese ist aber nicht nur eine „Dachgesellschaft", sondern muss versuchen, die Interaktion zwischen den Schwerpunktgesellschaften zu erhalten. Dies lässt sich am Beispiel der Entzündung, aber auch der Neoplasie, also an pathophysiologischen Mechanismen erleben, wie die DGIM in den letzten Jahren anlässlich der „Rüdesheimer Gespräche“ zeigen konnte. So wurde den Teilnehmern sehr deutlich, dass sich viel mehr Ähnlichkeiten zwischen Erkrankungen der Gelenke, des Verdauungstraktes, der Lunge und der Niere finden, als der auf „sein Organ“ fokussierte Wissenschaftler oder Kliniker annimmt.

\section{(2) Die Zeitschrift für Rheumatologie ist nun auch Organ der DGIM}

Es freut mich als Vorsitzender der DGIM daher sehr, dass die Zeitschrift für Rheumatologie die Mitteilungen der DGIM an ihre Leser kommuniziert.

Ich wünsche der Zeitschrift und ihren Herausgebern viel Erfolg!

Ihr

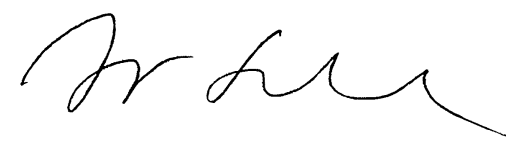

J. Schölmerich

1. Vorsitzender der Deutschen Gesellschaft für Innere Medizin

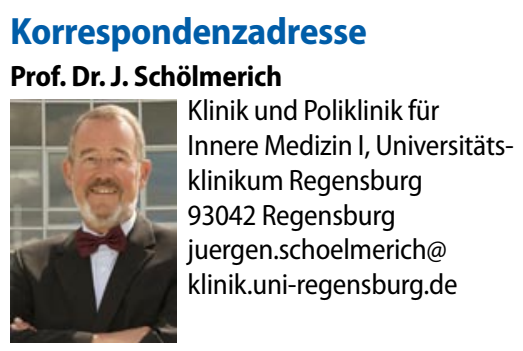

